\title{
Labour Income, Social Transfers and Child Poverty
}

\author{
Bruce Bradbury $^{1}$ (D) $\cdot$ Markus Jäntti $^{2}$ (D) $\cdot$ Lena Lindahl ${ }^{2}$
}

Accepted: 6 July 2018 / Published online: 21 July 2018

(C) The Author(s) 2018

\begin{abstract}
This paper documents the variation in living standards of the poorest fifth of children in rich (and some middle-income) nations, with a focus on the relative importance and interaction of social transfers (net of taxes) and labour market incomes. Overall, the crossnational variation in the disposable income of disadvantaged children is comprised equally of variation in market and transfer income (with the two negatively correlated). The English-speaking countries stand out as all having relatively low market incomes, but substantial variation in transfer income. Their low market incomes reflect low employment hours in Australia and primarily low hours in the UK and Ireland, while in the US and Canada low hours and low pay contribute equally. Comparing incomes prior to and after the 2008 financial crisis, the real disposable incomes of the poorest fifth decreased substantially in Greece, Spain and Ireland, but were relatively stable in other rich nations.
\end{abstract}

Keywords Poverty $\cdot$ Social transfers $\cdot$ Wages $\cdot$ Cross-national comparisons $\cdot$ LIS database

JEL Classification I32 $\cdot \mathrm{I} 38 \cdot \mathrm{J} 21$

\section{Introduction}

Child poverty has long been a central concern of policy analysis and research. Crossnational comparisons have been a powerful tool in this literature, both to identify those national models with particularly successful (or unsuccessful) outcomes for children and also to identify broader associations between possible determinants and outcomes. In much of this research, the primary focus has been on the role of income transfer policies in alleviating child poverty. This has been the case both for research which has addressed the broad

Bruce Bradbury

b.bradbury@unsw.edu.au

Markus Jäntti

markus.jantti@sofi.su.se

Lena Lindahl

lena.lindahl@sofi.su.se

1 Social Policy Research Centre, University of New South Wales, Sydney, Australia

2 Swedish Institute for Social Research, Stockholm University, Stockholm, Sweden 
socio-political determinants and effectiveness of social expenditures ${ }^{1}$ as well as research modelling the details of alternative tax and transfer policies. ${ }^{2}$

In this paper, we introduce a descriptive framework to examine the 'income packages' of disadvantaged families with children, one which permits a greater focus on the role of wages and income from employment. A decomposition approach is used to describe the cross-national and inter-temporal contributions of social transfers, wage rates and hours to the living standards of the poorest families with children.

The data for this decomposition are drawn from the Luxembourg Income Study database (2017), a cross-national database of harmonised household income survey data. This is supplemented with OECD-compiled data on cross-national patterns of low wages. The analysis includes a sample of rich OECD countries together with selected middle-income countries from Eastern Europe and East Asia. The outcome measures examined are the mean equivalent family income of the poorest one-fifth of children (in PPP-adjusted dollars), and this indicator relative to the median income of each country. Across nations, these two measures are strongly correlated with conventional measures of 'absolute' and relative poverty respectively. We present results on both, but mainly focus on the relative income measure which indicates the ratio between the living standards of disadvantaged children and the norm in their society.

In Sect. 2 of the paper, we review previous research looking at cross-national variation in child poverty, with a particular focus on the role of labour markets. We discuss our data in Sect. 3 and the decomposition framework in Sect. 4.

The results are presented in Sect. 5. Here we describe the wide variation in the combinations of transfer and market income received by disadvantaged children in different rich nations. Overall, market incomes and social transfers contribute roughly equally to the cross-national variation in relative living standards of the poorest children. The two measures are negatively correlated, with countries with greater transfers tending to have lower market incomes even when they are at the same point in the economic cycle. It is notable that disadvantaged children in the English-speaking countries all have low levels of market income, but the level of social transfers, and hence disposable income, varies significantly.

Trends in these patterns over the last two decades are then examined. Most countries were able to protect the relative living standards of the most disadvantaged children when market income fell after the 2008 financial crisis. However, this is partly due to the corresponding fall in median incomes. In real terms, the income of the bottom fifth fell dramatically in Spain and substantially in Ireland, by a small amount in Australia, the US, the UK, Germany and the Netherlands, but increased in Norway, Canada and Denmark.

Income from the market is then disaggregated further, into variation associated with national patterns of wage inequality and (imputed) hours worked. Among the Englishspeaking countries, low market incomes are associated with low wage rates in the US and Canada, but less so in the UK, Ireland and particularly Australia-where the low incomes of disadvantaged families stem from their relatively low employed hours.

\footnotetext{
1 For example, the debate about the anti-poverty impact of targeted versus universal payments starting with the work of Korpi and Palme (1998). See Van Lanker and Van Mechelen (2015) for a recent survey.

2 See for example Corak et al. (2005) and Whiteford and Adema (2007).
} 


\section{Recent Research on Cross-National Patterns of Child Poverty}

Previous research on the proximate determinants of cross-national child poverty variation has examined three main factors: family structure (particularly lone parenthood), social transfers and parental employment.

Bradbury and Jäntti (1999, 2001a, b) examined relative and absolute child poverty rates in rich countries during the 1990s. Though children in lone parent families were much more likely to be poor, variations in lone parenthood across nations did little to explain cross-national variations in poverty (e.g. both the US and Sweden had high rates of lone parenthood, but high and low poverty rates respectively). Across nations, variations in market incomes were found to explain more of the variation in disadvantaged children's family income than variations on social transfers.

Other research has focused on within-country changes in child poverty rates. Chen and Corak (2008) analysed changes in child poverty rates in 12 OECD countries during the 1990s. They observed little progress in reducing (relative) child poverty. In the countries where poverty rates did change, demographic forces played a limited role. Instead, changes in both labour markets and government support were found to be major causes of changing child poverty rates. The impact of reforms intended to increase labour supply differed across countries. For example, in both the United States and the Netherlands, significant policy changes were made to encourage labour market participation, but unlike in the US, child poverty rose in the Netherlands. In countries facing economic crises, the amount of income transfers from the state did not appear to have been increased to mitigate the effect of the crisis. Instead the opposite seems to have occurred in many countries. This is a result which has been echoed in more recent studies of the global financial crisis, where fiscal constraints have restricted spending (Bitler et al. 2014; Chzhen 2014).

An analysis by the OECD examined the target efficiency of transfers and the impact of employment on child poverty (Whiteford and Adema 2007). They identified three main groups of countries; the first characterized by below average levels of child poverty together with efficient tax and benefits systems that reduce levels even more (Belgium, Finland, Denmark and Sweden); the second group of countries with higher levels of child poverty and rather efficient redistribution (France, Australia); and a third group with inefficient redistribution systems (Mexico, Italy, Portugal, Spain, Japan, Switzerland). All countries with very low levels of child poverty had both low levels of joblessness and as well as high spending. However, a low level of joblessness on its own was not sufficient to ensure low poverty rates.

Whiteford and Adema also looked at the association between benefit levels and joblessness. Among the English-speaking countries, they found that more generous support to poor families was associated with more joblessness, potentially due to labour supply responses (see Adam et al. 2006 for a recent discussion in the British context). However, this association between benefit levels and joblessness association did not apply in the Nordic countries, where labour market policies to encourage employment were more prominent. These included both stronger work tests as well as greater assistance such as child care and training, which reinforced strong social expectations of parental employment.

Gornick and Jäntti (2012) used LIS data to examine cross-national variation in child poverty around 2005 . In this more recent data they found that household structure, especially lone parenthood, now accounted for a substantial part of the cross-national variation in child poverty. However, a comparison of poverty based on pre-tax, pre-transfer income with that based on post-tax, post-transfer (i.e. disposable) income suggested that it was the 
more precarious labour market position of lone mothers that was the chief reason-lonemother children had, relatively speaking, much higher market income poverty rates than children in two-parent families. Indeed, in a decomposition of poverty differences across countries, it was not variation in the characteristics of the children and their parents, but variation in the risks associated with a given set of characteristics, that accounted for the bulk of cross-national differences in child poverty.

Recently, attention has turned to the role of low wages in influencing family and child poverty-particularly in the US with its low minimum wages. A consensus seems to be emerging that modest increases in minimum wages in the US would have only a minor (or no) effect on labour demand and hence employment (e.g. Bernstein and Shierholz 2014). However, this evidence does not preclude an impact on labour demand at the higher wage levels found in other rich countries.

Even if there is no negative employment impact, higher minimum wages (or increases in low-end wages more generally) will not necessarily have a large direct anti-poverty impact. This depends on whether wage income is above or below the poverty line prior to the increase, as well as the incomes of other family members. Indeed, most US studies show that minimum wage increases would only have a small impact on poverty rates-though they nonetheless would tend to help families in the lower part of the income distribution. ${ }^{3}$

Despite this weak direct link between minimum wages and poverty, the cross-national correlation between low wages and child poverty is very strong (Bradbury and Jäntti 1999; UNICEF 2000). This contrast remains something of a puzzle. It could represent the fact that minimum wages are not the same as low wages more generally, or might represent the impact of other indirect links. If wages are low, a policy objective of maintaining work incentives may require low benefits for those not working (unless in-work benefits are increased or other non-income assistance is used). There could also be a reverse causal linkage, with generous out-of-work benefits requiring employers to increase wages to attract workers. More generally, political decisions about equity in one sphere (e.g. wage bargaining institutions) might also carry across to other policy areas such as social transfers.

\section{Data}

Our primary data source is the Luxembourg Income Study (LIS) database (2017). This is a large cross-national research database of harmonised household income surveys from rich and middle-income countries. The database comprises person and household-level records from these surveys, with access via remote submission of analysis programs (see www. lisdatacenter.org for documentation). The main strength of the LIS database is its harmonisation and detailed disaggregation of the different components of household incomes, a key requirement for our decomposition approach. It also includes information on demographic and employment characteristics, though there are variations in the degree of detail available in different countries.

One key omission, however, is harmonised data on wage rates. Though the LIS study is generally able to harmonise wage income (usually annual wage income), information on the hours of work corresponding to that wage income is less comparable. Indeed, despite

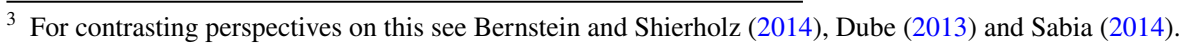


its importance for economic and social policy, cross-nationally comparable data on the distribution of wage rates is sparse.

The most comprehensive source of such data is that compiled by the OECD (see OECD 2016). Among other key statistics, this dataset reports the ratios between 10th and 90th percentiles and median wages, and is available for most OECD countries from 2000 onwards. As with most OECD data collections, these data are supplied by national statistical agencies. Because of differing data availability, there remain some cross-national differences in the variable definitions (though the within-country time-series are generally consistent). Some countries have data from household surveys, some from employer surveys or tax register data, some countries report the distribution of monthly or weekly wages for fulltime workers, while others have direct hourly wage data or report the distribution of annual wages for full-year full-time workers. For our analyses that include wage inequality, we use this data directly as reported by the OECD. ${ }^{4}$ Note, however, that this wage data is not disaggregated by demographic characteristics such as parenthood. Our conclusions about the impact of wage inequality on the incomes of families with children thus rest on an approximating assumption that these cross-national differences in overall wage inequality are also found in the cross-national differences of wage inequality among parents with children.

Several adjustments are made to the LIS data to remove outliers. Each of the income components is censored at zero (i.e. negative values are set to zero). This mainly affects the self-employed component of earnings income, where large negative income is often associated with large asset bases and so does not reflect low living standards. Tax liabilities are also censored at an upper boundary of $90 \%$ of gross income. Very high tax liabilities often represent higher incomes in previous years, and again the very low disposable income they imply would unlikely to be an indicator of low current living standards.

Though the LIS data is the best cross-national collection of data on household income disaggregated by income source, income definitions in some countries do restrict our analysis. Our primary decomposition is that between income from the market (wages, capital income etc.) and income from social transfers (minus income taxes and social insurance contributions). The first problem is that in some countries (denoted as Net or Mixed countries in the LIS documentation), income taxes are not separately identified, but instead are removed from market income components, with only net market incomes reported. For the most recent waves of LIS data in rich countries (shown in Table 1 below), this affects the estimates for France, Italy, Russia and Slovenia. In these countries, market incomes are thus underestimated and net social transfers over-estimated (with disposable incomes unaffected). However, for the analysis in this paper, this is probably only a minor distortion, as income taxes are generally a small proportion of income for families in the bottom fifth of the income distribution.

More important is that in Italy and Greece, some family-related social transfers are included with wage income in the LIS database. This is because they are received as wage supplements by (usually) the child's father. Again, this does not affect disposable income, but does lead to distortion of the decomposition in the opposite direction-market incomes are too high and net social transfers too low. This distortion should be kept in mind when considering the results for these two countries.

\footnotetext{
4 A preliminary analysis comparing this data with that available for a sub-set of LIS countries where fullyear full-time employment can be identified does not reveal any significant associations with the different sources of data in the OECD collection. We impute a wage distribution estimate for Spain in 2013 using data available in the LIS file.
} 


\section{Decomposition Framework}

As with most of the literature comparing poverty in rich nations, our primary focus is on the living standards of disadvantaged children relative to the norm in their society. This is often summarised using a relative poverty measure which defines children as poor if their family disposable income, adjusted for family size, is below a threshold based on average community living standards-commonly 50 or $60 \%$ of median income in the country in which they live.

Our primary outcome measure is closely related to this - the average household disposable income of the poorest one-fifth of children in the society, relative to the same median income measure. Figure 5 in the "Appendix" shows this to be strongly correlated with national half-median poverty rates. Some results showing real incomes, akin to an 'absolute' poverty measure, are also presented. All incomes are adjusted for household size using an equivalence scale factor ${ }^{5}$ of $(N \text { Adults }+0.75 \times N \text { Children })^{0.8}$. Children are defined as people aged under 18 .

Unlike conventional poverty rates, our index of living standards is additive across households, which permits more straightforward decomposition by either income source or demographic grouping. In this paper, the contribution of different income components to the income of this bottom fifth is described using a decomposition by income source as outlined in Eq. (1). All the income components (denoted by capital letters) are relative to median disposable income in the country $(c)$ and year of observation $(t)$.

$$
\begin{aligned}
D_{t c} & =M_{t c}+T_{t c} \\
M_{t c} & =K_{t c}+E_{t c} \\
E_{t c} & =w_{t c} h_{t c} E_{Q 3 t c}
\end{aligned}
$$

where $D_{t c}=$ mean disposable income of bottom fifth, $M_{t c}=$ mean market income of bottom fifth, $T_{t c}=$ mean net social transfers of bottom fifth, $K_{t c}=$ mean capital (and misc) income of bottom fifth, $E_{t c}=$ mean earnings of bottom fifth, $E_{Q 3 t c}=$ mean earnings of middle fifth, $w_{t c}=\frac{w_{10 t c}}{w_{50 t c}}$, wage rate of 10 th relative to 50th percentiles, $h_{t c}=\frac{E_{t c}}{w_{10 t c}} / \frac{E_{Q 3 t c}}{w_{50 t c}}$, (imputed) relative hours of bottom to middle.

The first step is the decomposition of disposable income into market income $M_{t c}$ and net social transfers, $T_{t c}$ (all components relative to the median). The latter is defined as household social income transfers received minus income taxes and compulsory social insurance contributions. In-work benefits and tax credits are included in $T_{t c}$ (except for Italy and Greece as noted above).

Market income is further disaggregated into income from capital, $K_{t c}$, and earnings $E_{t c}$. Self-employment income is included in earnings (it is assumed that for the bottom fifth, business capital makes negligible contribution to self-employment income), and private income transfers and miscellaneous income are included with capital income.

\footnotetext{
5 This is the scale used to produce the results in Bradbury and Jäntti (1999, 2001a, b). Thanks to a vigilant referee, we must report that the text in all three of these earlier papers erroneously describes the equivalence scale parameters used as being 0.7 and 0.85 instead of 0.75 and 0.8. Bradbury and Jäntti (1999) also undertake a sensitivity analysis and find that while equivalence scale parameters matter for the relative risk of poverty of different household types (in particular, whether children or the elderly are more at risk of poverty within a country depends on this), cross-national rankings of child poverty change little when even more substantial changes are made to the equivalence scale.
} 
Earnings, in turn, can be decomposed into the product of wage rates and hours worked. A synthetic estimate is used which draws on the income data of the LIS dataset and the information on wage inequality available in the OECD collection. The OECD compiles information on the ratio to 10th to 50th percentile wage rates for the whole population. This ratio is assumed to apply to parents to derive a broad indication of hours of work in bottom income households relative to those in the middle of the income distribution $\left(h_{t c}\right)$. While only a broad approximation, this does permit an initial description of how the crossnational variation in relative earnings is due to either variation in wage inequality or hours worked. ${ }^{6},{ }^{7}$

Using this decomposition, we can also describe how the different factors contribute to each country's deviation from the cross-national average. Equation 2 shows a decomposition of the relative disposable income of the bottom fifth in each country minus that of the average country, into the difference of each component of income from the cross-national average (averages across countries are denoted by overbars). ${ }^{8}$ This formulation allows us to decompose variation in the disposable family income of children into that due to the different components of income and the wage and hours components of earnings.

$$
\begin{aligned}
D_{t c}-\bar{D} & =\left(T_{t c}-\bar{T}\right)+\left(K_{t c}-\bar{K}\right)+\left(E_{t c}-\bar{E}\right) \\
& \approx\left(T_{t c}-\bar{T}\right)+\left(K_{t c}-\bar{K}\right)+\bar{E}\left(\frac{w_{t c}-\bar{w}}{\bar{w}}+\frac{h_{t c}-\bar{h}}{\bar{h}}+\frac{E_{Q 3 t c}-\overline{E_{Q 3}}}{\overline{E_{Q 3}}}\right)
\end{aligned}
$$

\section{Results}

Table 1 summarises the most recent LIS data available for rich countries. 'Rich' is defined broadly-having median equivalent disposable income greater than USD9000. The income estimates are in 2013 USD, adjusted using within-nation consumer price indices and crossnation OECD purchasing power parity indices (PPP). The most recent year with data is generally after the financial crisis of 2008-2009 (Sweden, in 2005, and Japan in 2008, are exceptions).

The first data column of the table shows the median equivalent disposable income of all people in the country in the year of observation. The second column shows the mean equivalent disposable income of the bottom fifth of children. Our primary dependent variable is the ratio of these two values-shown in the third data column and denoted by (D). This is strongly correlated with conventional half-median poverty rates $(r=-0.98$ for the

\footnotetext{
${ }^{6}$ Note that our imputed hours index for each quintile group is a 'ratio of means' rather than a 'mean of ratios'. That is, we are not able to calculate hours for each household and then average this; instead we divide average earnings for the quintile by (an indicator of) the average wage rate in the quintile (in both cases relative to the middle quintile). The two measures are identical if everyone in the quintile group has the same wage rate, but otherwise may be different.

7 Following the main tradition of poverty research, this paper analyses the components of family monetary income (including some near-monetary equivalents). We do not incorporate the value of parent's time. Nonetheless, we should note that if there are two countries where earnings are the same, but one has a higher relative wage rate, then the longer work hours in the other country will imply lower parental (and possibly child) welfare.

${ }^{8}$ The approximation in the second line arises from a first order Taylor series expansion of the multiplicative components of earnings.
} 


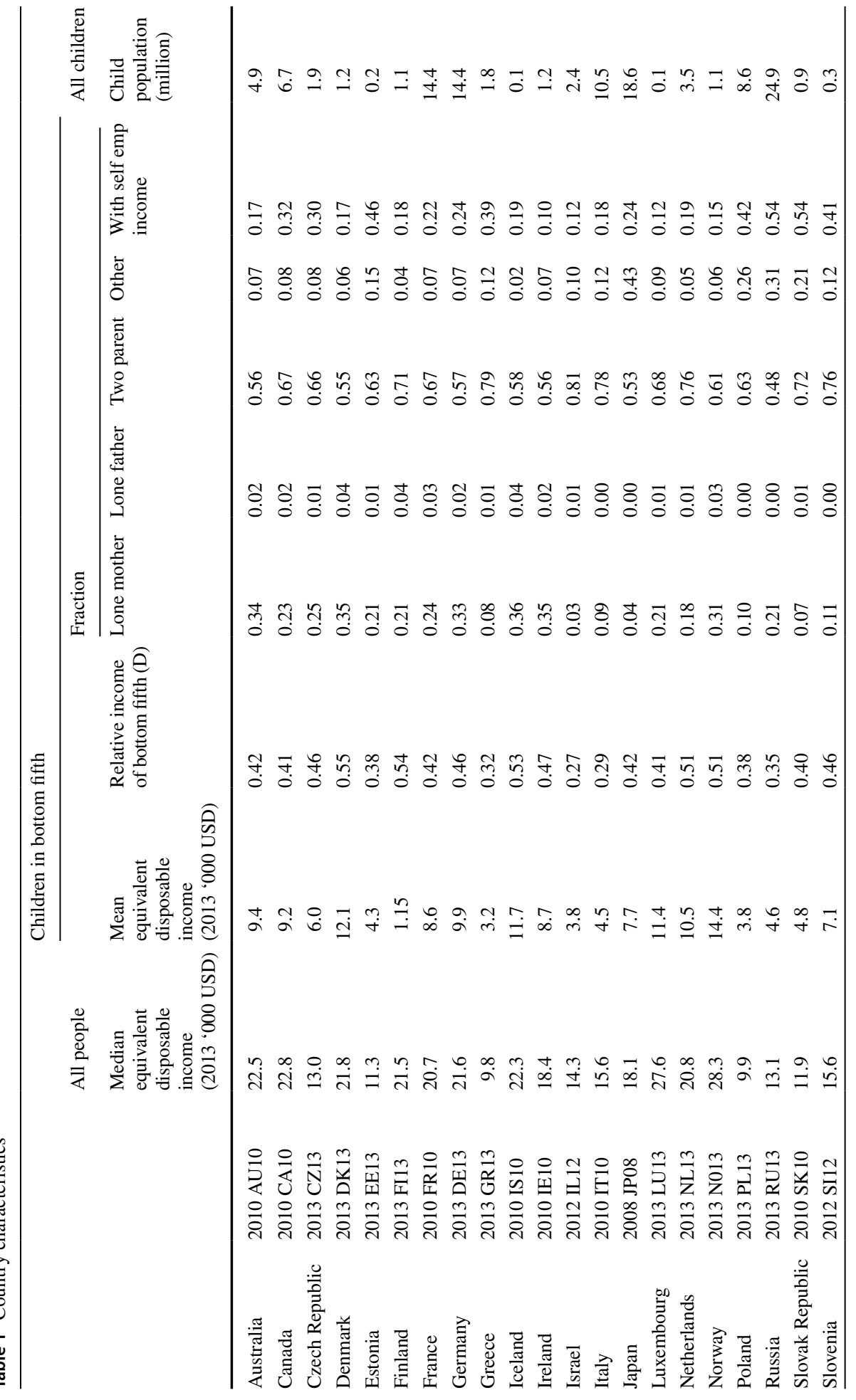




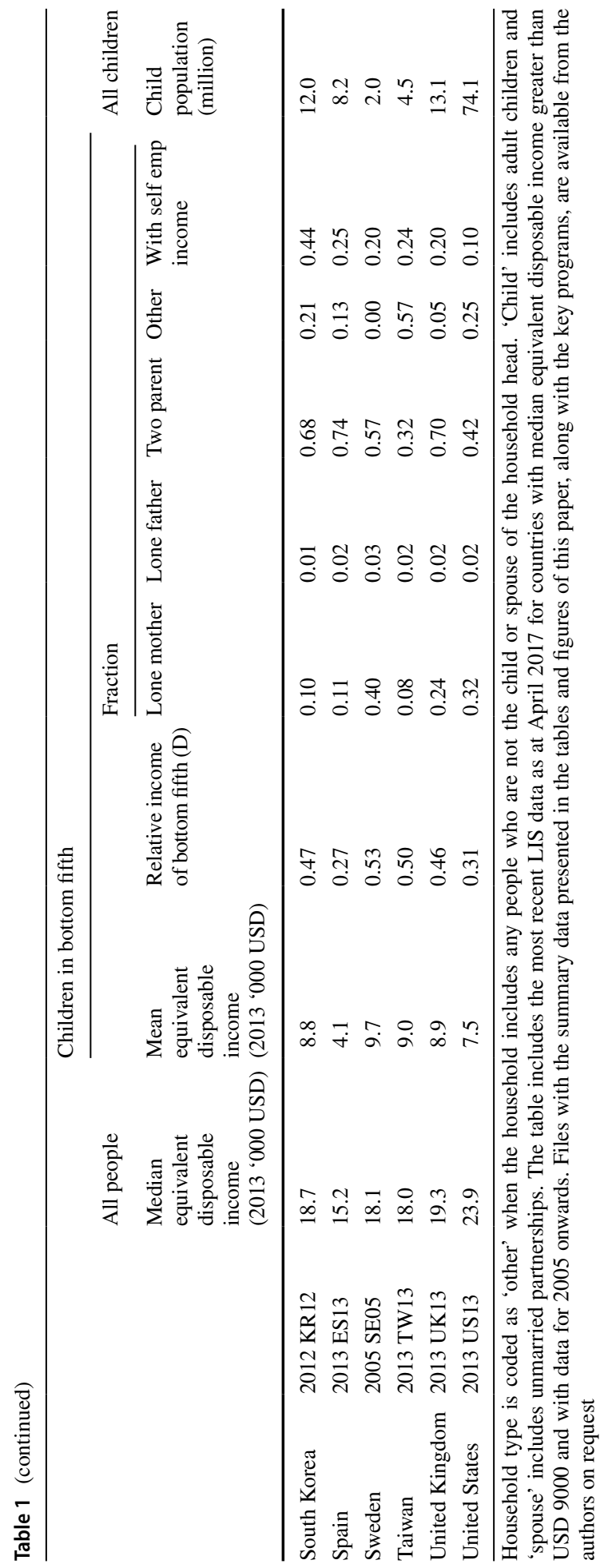


observations in this table). ${ }^{9}$ At the bottom, with bottom-fifth incomes of below one-third the median living standard and with child poverty rates above $20 \%$ ("Appendix Fig. 5") are Greece, Israel, Italy, Spain and the United States. At the other extreme are the Nordic countries with average incomes of the bottom fifth above $50 \%$ of the median.

The size of these countries varies dramatically, with child populations ranging from 0.1 in Iceland to 74 million in the United States (last column). Nonetheless, given the central role of the nation state in setting both social protection and labour market policies we maintain this as our unit of analysis here.

Lone parenthood rates for children in bottom-fifth households are low in East Asia and in Southern and Eastern European countries, while in most other countries at least a fifth or more of these children live with their mothers only. The 'other' family type-mainly multigenerational families - is most prominent in East Asia and Russia, though a quarter of US children live in these larger families.

The proportion of children in bottom-fifth households with any self-employment income also varies significantly. Broadly speaking, self-employment rates are below a quarter in the high-income countries - those with equivalent median incomes above USD 16,000 (Canada and Korea are the exceptions). Lower-income countries tend to have selfemployment rates of between 30 and 55\% (Spain, Italy and Israel are the exceptions).

The interactions between the labour market and social protection systems are often very different for the self-employed. Moreover, it is sometimes argued that income is a poor indicator of their consumption opportunities (because of both unreported income and opportunities for wealth deaccumulation). For these reasons, we also present in the "Appendix" some of our key results for the sub-sample of bottom fifth children who live in households with no self-employment income. Though this group has a lower share of income from the market, the cross-national pattern is very similar to that found for the overall population of bottom-fifth children.

The decomposition of bottom fifth relative disposable income (D) into market income (M) and net social transfers (T) is shown in Fig. 1. As noted above, all incomes are bottom fifth averages of the equalised household income of children, relative to the overall median disposable income in their country and year. This figure shows the relative market income of the bottom-fifth of children (bottom axis), their average relative transfers (left axis) and contours of $\mathrm{D}=\mathrm{M}+\mathrm{T}$ (top-left to bottom-right contours).

Countries where disadvantaged children have higher disposable incomes (relative to their national median) thus lie further to the top-right of the figure. For example, the Nordic countries all have relative disposable income more than half the median, while disadvantaged children in Israel, Spain and Italy average less than $30 \%$ of the median. Children in countries lying above the ray from the origin have on average more than half their income from transfers.

Notable is the wide variation in market/transfer combinations even among countries with similar relative living standards. For example, among countries with D between 0.4 and 0.5 , transfers (minus taxes and social insurance contributions) range from negative in Taiwan, to almost 4 times market income in Ireland.

The low transfers in Italy and Greece partly reflect the measurement issues described in Sect. 3 above. In these countries, many family-related transfers are included as part of wages rather than transfers. This explanation does not apply to the East Asian nations/

\footnotetext{
9 The real incomes of the bottom fifth are just as strongly correlated with a logit transformation of an 'absolute' poverty based on the US poverty line $(\mathrm{r}=-0.98)$.
} 


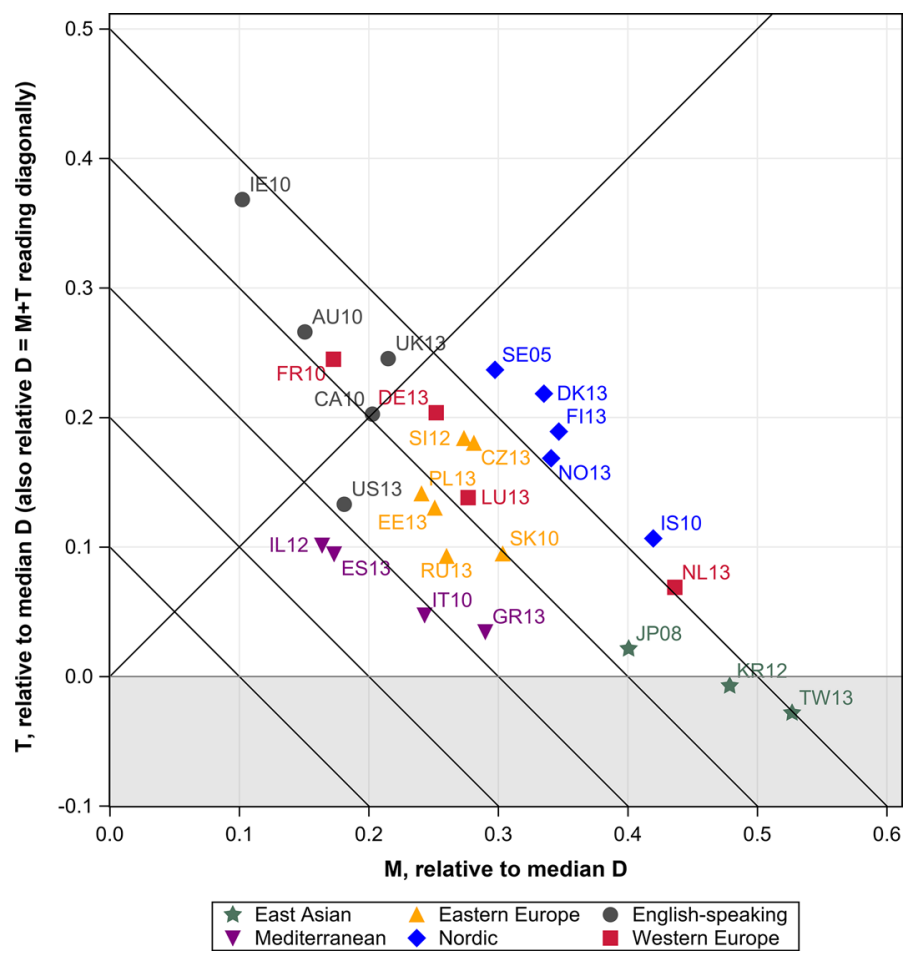

Fig. 1 Children in the bottom-fifth of disposable income: average market income (M), Net social transfers $(\mathrm{T})$ and disposable income $(\mathrm{D}=\mathrm{M}+\mathrm{T})$-all relative to median income. Note $\mathrm{T}=$ Average net social transfers, $\mathrm{M}=$ Average market income. Lines from top-left to bottom-right denote equal contours of relative disposable income $(D=M+T)$, which can be read off from their intersection with the $y$-axis. All income measures are relative to median equivalent disposable income. The ray from the origin denotes $\mathrm{T}=\mathrm{M}$. See Table 1 for country abbreviations. Note that for IT and GR, some social transfers are received as part of wages-which means their data markers should be shifted up and to the left to be comparable. A smaller distortion in the opposite direction also exists for FR, IT, RU and SI, where income measures are collected net of taxes (less important because taxes are low for the bottom quintile group)

regions shown here (Japan, South Korea and Taiwan) which have low net transfers to disadvantaged families with children (negative in two cases) but high market income.

Distinctive patterns are also apparent for the mix of market and transfer incomes in the different sub-groups of countries. ${ }^{10}$ The English-speaking countries (including Canada), all lie on the left-hand side of Fig. 1, with the average market income of bottom-fifth children below $21 \%$ of national median disposable income. But differences in social transfer generosities mean that their disadvantaged children have very different disposable income outcomes-ranging from around one-third of median income in the US to almost one-half in Ireland. This Irish pattern is a result of a combination of relatively high transfers combined

\footnotetext{
10 The grouping here is language/location based rather than political- the EU countries are spread across five groups. It closely corresponds to the groupings of 'welfare regimes' developed by Esping-Andersen (1990) and subsequent researchers.
} 
with low employment intensity and a lack of emphasis on employment activation policies (Grubb et al. 2009; Watson et al. 2012).

On the other hand, disadvantaged children in the Nordic countries all have similar relative disposable incomes, but vary in the mix of market and transfer incomes that comprise this. A strong emphasis on activation policies, means however, that in all cases more than half the income of the families of disadvantaged children is from the market.

The Swedish data here is from before the financial crisis. Other data sources suggest that child poverty in Sweden decreased between 1996 and 2006 due to rising real incomes in child households, followed by stagnating real incomes at the lower part of the income distribution from 2006 and onwards. The result was an increase in relative but no change in absolute income poverty in child households (Mood and Jonsson 2016). Björklund and Jäntti (2011) also show that in lone-parent families, poverty has increased rapidly in Sweden, especially after 2010 .

The four Western European countries included here have an even wider mixture of transfer and market incomes, but a similar level of relative disposable income (lower than in the Nordic countries). The Eastern European countries are clustered in the middle of this relative income distribution (but recall that their real income levels are substantially lower than for most other countries-see Table 1).

In "Appendix" Fig. 6 we show how these income packages vary across household composition. The cross-national pattern of incomes in each family type broadly mirror the overall pattern. Those countries with higher relative mean incomes for all bottom-fifth children achieve this by enabling children in both family types to have high incomes. Similarly, relatively high shares of income from the market generally apply to both family types.

Nonetheless, there are some consistent differences. Two-parent families have a greater share of their income from the market, with all except Irish families receiving half or more of their income from this source. Indeed, Irish two-parent families are distinctive in receiving relatively high transfers and low market incomes-closer to the lone-mother model. The unusually low transfer/high market combination in the Netherlands also applies only to two-parent families.

Finally, we note that self-employment in the households of bottom-fifth families does not explain these cross-national variations. Figure 7 in the "Appendix" presents the same data as Fig. 1, except here just for the sub-set of children in households with no selfemployment income. Market incomes are a little lower in most countries, but otherwise the patterns are largely unchanged (self-employment appears to explain some of the low transfer share of children in the Netherlands).

These figures provide a simple framework for describing the relative importance of different policy interventions on the living standards of disadvantaged children. A one percent increase in minimum wages, for example, will have little 'first-round' ${ }^{11}$ impact on the living standards of disadvantaged children in the countries at the top-left of the figures (e.g. Ireland) - since wages contribute only a small component of their incomes. Similarly, the same percentage increase in transfers will have little impact on the incomes of children in the earnings-dependent East Asian countries.

Using data for the 1990s, Bradbury and Jäntti (2001a) found greater cross-national variation in market income than in net transfers. This more recent data, with a broader range of

${ }_{11}$ That is, before any labour supply or demand responses. 
countries, also has more market income variation-but here the variation in the two components is not very different (the standard deviation of D, M and T respectively in Fig. 1 is $0.08,0.10$ and 0.09). In this sense, each component can be said to 'explain' about half of the cross-national variation in the relative living standards of disadvantaged children.

However, the two components are not independent, with the overall variation in D less than the sum of the two components because of the strong negative correlation between the two $(-0.64)$. That is, the countries where the families of the most disadvantaged children have higher market incomes tend to have lower social transfers.

Several causal mechanisms might explain this. One is that social transfers act as a compensatory mechanism for poor labour market outcomes. In a time-series setting, this might occur when the increased unemployment associated with a recession leads to increased expenditure on unemployment insurance and related social assistance programs. However, in Fig. 1, most countries are observed in the same (2010-2013) period and so this 'automatic stabiliser' explanation is of limited relevance. Other explanations include that this correlation might reflect reductions in labour supply due to high social benefits in some countries, or be an outcome of some countries directing more resources to employment support (e.g. training and child care) rather than income transfers.

The within-country pattern of change over time, including the role of 'automatic stabilisers' is addressed in Figs. 2 and 3 for countries where we have a significant run of data. The first figure shows how the bottom-fifth group fared, relative to the median, since the early 1990s (the last year in each line corresponds to the points in Fig. 1).

This relative measure is most informative for contrasting the situation of the most disadvantaged children with the income norms dominant in their society. However, when examining changes over time, the real incomes of the bottom fifth are also of interest since past, rather than median incomes, might be used as a welfare reference point. These real income levels are shown in Fig. 3.

In most of the countries for which we have this time-series data, there has been substantial real income growth for the most disadvantaged children over the last two decades, with substantial shifts to the top-right in Fig. 3. There are some notable exceptions however. In Spain, there was substantial real income growth for disadvantaged children up until 2007, but by 2013 incomes had returned to their 1990 levels. Greece experienced an even larger fall in market and total incomes after 2007, also returning to early 1990s disposable income levels by $2013 .^{12}$

In both countries, the main changes were to market income, with increases in transfer incomes only partially offsetting the fall in market income after the global financial crisis (GFC). In the US the impact of the financial crisis was more muted, but the long-term increase in real incomes at the bottom was also very small.

Many other countries experienced substantial market income falls after the GFC (i.e. comparing 2007 with later years). In most cases, though, transfers increased substantially, so that net incomes remained relatively stable (or even increased slightly). Ireland, a country that was strongly affected by the financial crisis, had a large fall in market income without any increase in net transfers - though transfers to disadvantaged families were already relatively high prior to the crisis (Grubb et al. 2009).

For most countries, the long-term pattern of real income growth shown in Fig. 3 did not imply increasing relative living standards for the bottom-fifth of children-because there

\footnotetext{
12 The pre-2007 Greek data in LIS has a different definitional split between market and transfer income (on a net income basis) and so is not shown in the figure.
} 


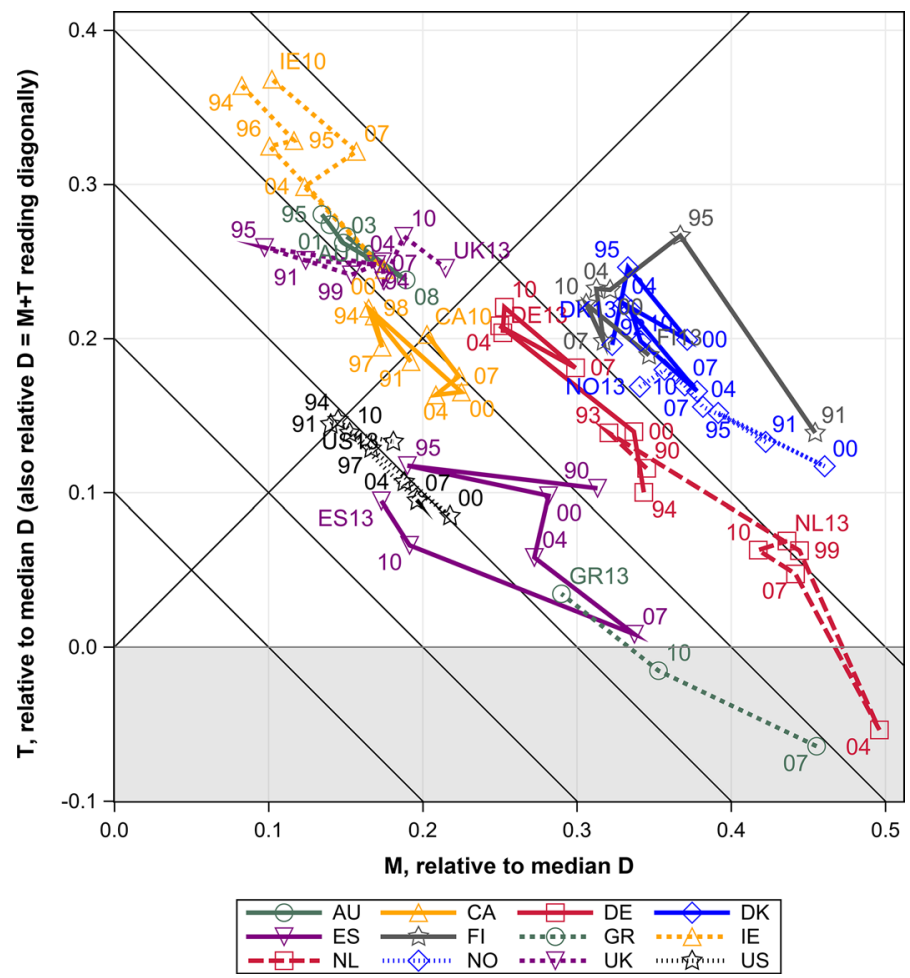

Fig. 2 Trends since the 1990s: Incomes relative to the median. Note $\mathrm{T}=$ Average net social transfers, $\mathrm{M}=$ Average market income. Lines from top-left to bottom-right denote equal contours of disposable income $(\mathrm{D}=\mathrm{M}+\mathrm{T})$, which can be read off from their intersection with the y-axis. All income measures are relative to median equivalent disposable income. The ray from the origin denotes $\mathrm{T}=\mathrm{M}$

was equal or stronger growth in the middle of the income distribution. ${ }^{13}$ In Fig. 2, the most common pattern for the relative income package of disadvantaged children was of diagonal movement-with relative living standards remaining constant while the share of income from the market fluctuated with labour market circumstances. Again, Spain and Greece were exceptions, where the living standards of children in the bottom-fifth group dropped further than median incomes after the GFC. There was also a similar fall in Finland at the end of the 1990s. A less dramatic exception in the opposite direction is the UK, where median incomes fell more than bottom fifth incomes after the GFC.

In Fig. 8 in the "Appendix", the real incomes of bottom-fifth children in households with no self-employment income is presented. The trends over time are largely the same as in Fig. 3. Notable, however, is that the 2004 result for the Netherlands is more consistent with that in other years, implying an atypical treatment of self-employment income in that

\footnotetext{
13 See Whelan et al (2017) for a discussion of trends in incomes and other stress indicators in European countries.
} 


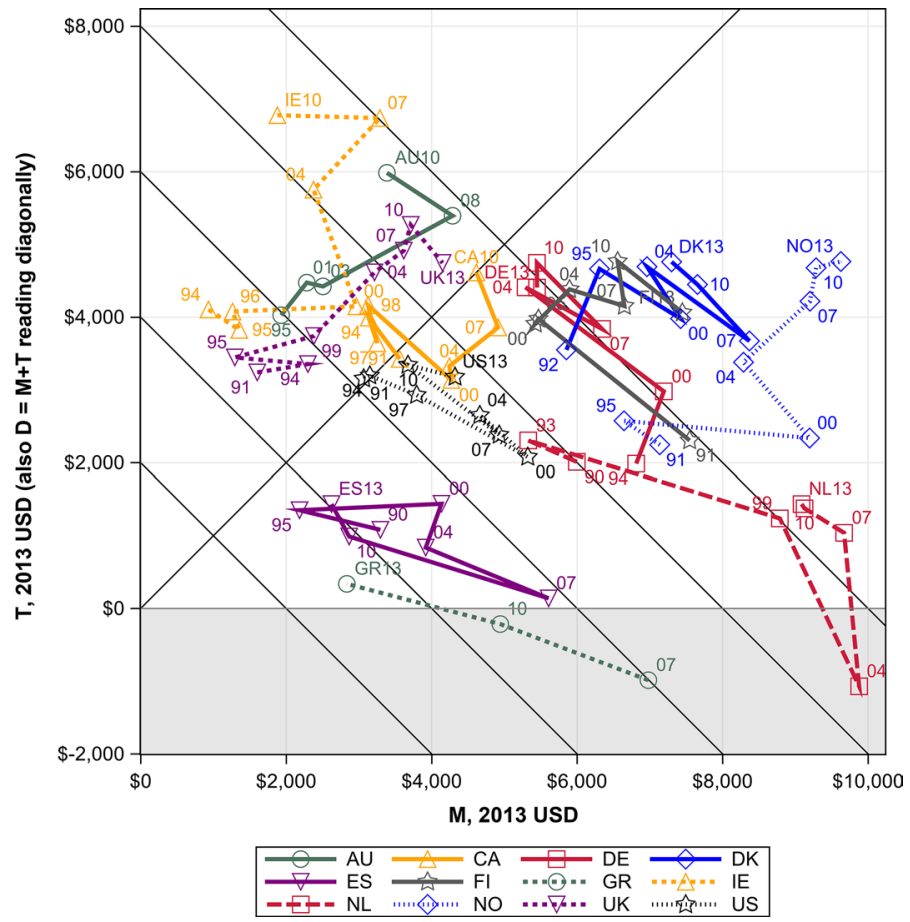

Fig. 3 Trends since the 1990s: 2013 USD. Note: T Average net social transfers, M Average market income. Lines from top-left to bottom-right denote equal contours of disposable income $(\mathrm{D}=\mathrm{M}+\mathrm{T})$, which can be read off from their intersection with the y-axis. All income measures are in 2013 USD (single person equivalent). The ray from the origin denotes $\mathrm{T}=\mathrm{M}$

year. ${ }^{14}$ The pattern in Ireland after the GFC is now somewhat different, with a decrease in transfer incomes among the non-self-employed bottom-fifth children.

Returning to the current cross-national distribution, Table 2 reports the income components as per Eq. (1) for the most recent years where we have wage rate data. Countries here are sorted in descending order of $\mathrm{D}$, the mean disposable income of children in the bottom fifth (relative to the population median).

The first three data columns of this table replicate the information shown in Fig. 1 (though for earlier years in some cases). The $\mathrm{K}$ income components (capital and private transfers) are generally very small, and so the E component (earnings) is close to $\mathrm{M}$. It reports the mean earnings of the bottom fifth, relative to the national median disposable income. The wage inequality column, w, is from the OECD wage inequality database and reports the wage at the 10th percentile of the distribution relative to the median.

Following Eq. (1) we employ an assumption that this measure of wage inequality also applies to the parental wage ratio between the bottom and middle fifths of the child disposable income distribution, and use this to derive an imputed hours inequality variable. The

\footnotetext{
14 There have been a number of changes to employment and taxation in the Netherlands which have led to a substantial increase in self-employment in the decade after 2003 (Weistra 2016). We speculate that incentives to declare income in different years associated with these changes might have produced the negative social transfers (i.e. high taxes) shown for the Netherlands in 2004 in Fig. 3.
} 
Table 2 Children in the bottom fifth: Income components relative to population median disposable income

\begin{tabular}{|c|c|c|c|c|c|c|c|c|c|}
\hline & & $\mathrm{D}$ & $\mathrm{T}$ & M & $\mathrm{K}$ & $\mathrm{E}$ & $\mathrm{w}$ & $\mathrm{h}$ & EQ3 \\
\hline Denmark & 2010 & 0.54 & 0.20 & 0.34 & 0.02 & 0.33 & 0.69 & 0.39 & 1.20 \\
\hline Finland & 2013 & 0.54 & 0.19 & 0.35 & 0.02 & 0.33 & 0.68 & 0.48 & 1.01 \\
\hline Sweden & 2005 & 0.53 & 0.24 & 0.30 & 0.04 & 0.25 & 0.74 & 0.37 & 0.95 \\
\hline Iceland & 2010 & 0.53 & 0.11 & 0.42 & 0.05 & 0.37 & 0.58 & 0.63 & 1.02 \\
\hline Slovenia & 2010 & 0.52 & 0.16 & 0.36 & 0.02 & 0.34 & 0.63 & 0.67 & 0.82 \\
\hline Norway & 2013 & 0.51 & 0.17 & 0.34 & 0.00 & 0.34 & 0.62 & 0.54 & 0.99 \\
\hline Netherlands & 2010 & 0.48 & 0.06 & 0.42 & 0.01 & 0.41 & 0.62 & 0.57 & 1.16 \\
\hline Ireland & 2010 & 0.47 & 0.37 & 0.10 & 0.02 & 0.09 & 0.52 & 0.23 & 0.71 \\
\hline Czech Republic & 2010 & 0.46 & 0.14 & 0.32 & 0.04 & 0.28 & 0.52 & 0.62 & 0.86 \\
\hline United Kingdom & 2013 & 0.46 & 0.25 & 0.21 & 0.01 & 0.20 & 0.56 & 0.55 & 0.67 \\
\hline Luxembourg & 2010 & 0.46 & 0.14 & 0.32 & 0.01 & 0.31 & 0.64 & 0.62 & 0.79 \\
\hline Germany & 2013 & 0.46 & 0.20 & 0.25 & 0.03 & 0.22 & 0.55 & 0.41 & 0.99 \\
\hline South Korea & 2006 & 0.45 & 0.01 & 0.44 & 0.05 & 0.40 & 0.47 & 0.83 & 1.00 \\
\hline Japan & 2008 & 0.42 & 0.02 & 0.40 & 0.01 & 0.39 & 0.61 & 0.66 & 0.97 \\
\hline France & 2010 & 0.42 & 0.25 & 0.17 & 0.01 & 0.16 & 0.67 & 0.34 & 0.69 \\
\hline Australia & 2010 & 0.42 & 0.27 & 0.15 & 0.02 & 0.13 & 0.60 & 0.27 & 0.84 \\
\hline Poland & 2010 & 0.41 & 0.14 & 0.27 & 0.02 & 0.25 & 0.51 & 0.68 & 0.72 \\
\hline Canada & 2010 & 0.41 & 0.20 & 0.20 & 0.01 & 0.19 & 0.51 & 0.42 & 0.90 \\
\hline Slovak Republic & 2010 & 0.40 & 0.09 & 0.30 & 0.01 & 0.29 & 0.55 & 0.64 & 0.83 \\
\hline Estonia & 2010 & 0.40 & 0.16 & 0.23 & 0.01 & 0.22 & 0.48 & 0.47 & 0.99 \\
\hline Greece & 2010 & 0.34 & -0.02 & 0.35 & 0.02 & 0.33 & 0.62 & 0.51 & 1.04 \\
\hline United States & 2013 & 0.31 & 0.13 & 0.18 & 0.01 & 0.17 & 0.48 & 0.42 & 0.84 \\
\hline Israel & 2010 & 0.29 & 0.12 & 0.17 & 0.03 & 0.14 & 0.53 & 0.36 & 0.72 \\
\hline Italy & 2010 & 0.29 & 0.05 & 0.24 & 0.01 & 0.23 & 0.69 & 0.45 & 0.75 \\
\hline Spain & 2013 & 0.27 & 0.09 & 0.17 & 0.01 & 0.16 & 0.54 & 0.39 & 0.77 \\
\hline Mean & & 0.43 & 0.15 & 0.28 & 0.02 & 0.26 & 0.58 & 0.50 & 0.89 \\
\hline Correlation with D & & 1.00 & 0.39 & 0.50 & 0.29 & 0.48 & 0.37 & 0.21 & 0.45 \\
\hline
\end{tabular}

Variables defined as in Eq. (1). D, T, M, K, E, and EQ3 from LIS database. Wage p10/p50 ratio (w) from OECD wage inequality database. Hours (h) derived from $\mathrm{E}$ and $\mathrm{w}$ following Eq. (1). Note that $\mathrm{D}=\mathrm{T}+\mathrm{K}+$ w.h.EQ3. Mean and correlation are unweighted. Italic font denotes the highest $1 / 3$ of items in each column, and bold font the lowest

variable $h$, thus represents the ratio of hours worked in the bottom fifth relative to hours worked in families in the middle of the distribution. As expected, it is always below 1.

Finally, the 'EQ3' column reports the mean earnings of the middle fifth of children, relative to median disposable income in the population (all measures adjusted for family size). It captures the relative income of children's households compared to the overall population, as well as the relationship between gross earnings and disposable income in the middle of the distribution.

Evident in the table is the substantial correlation between disadvantaged children's relative living standards and the degree of wage inequality in their country $(r=0.37)$. That is, countries with relatively high wages at the bottom of the distribution tend to have high incomes for disadvantaged families. The main exception to this is Italy, which has relative 
wages like those in Denmark and Finland, but much lower relative disposable incomes because of low transfers ( $r=0.53$ if Italy is excluded). Greece is similar, in that it has low disposable income but near-average wage inequality. Ireland is an exception in the opposite direction with low wages but high transfers.

Subject to the caveats about the different scope of the wage inequality indices, this table can also be used to describe the proximate drivers of the employment income patterns in different countries. Disadvantaged children in the US, for example, have a relatively low market income ( $18 \%$ of median income, compared to a cross-national mean of $28 \%$ ). Lowend relative wages are much less than average, but not enough to entirely explain this, and so imputed relative hours (hours of the bottom compared to the middle) are also lower than average, though now in the middle $1 / 3$.

The decomposition following Eq. (2) is shown in Table 3. In this case, each component shows its contribution to the deviation from the (unweighted) cross national mean of relative disposable income. For example, in the first country, Denmark, the relative disposable income is $11 \%$ points higher than the cross-national average. Five percentage points arises from greater than average social transfers and $6 \%$ points from a higher market income. This reflects a higher contribution from earnings, which in turn is comprised of a positive effect from the wage distribution (p10 wages are relatively high in Denmark), an imputed negative effect of relatively low working hours, plus a positive effect of high earnings among the parents of middle-income children (relative to the national median). In short, we can describe the relatively high disposable income of disadvantaged children in Denmark as arising from relatively high transfers, plus relatively high earnings for the average family with children and relatively high wages for those at the bottom, offset by disadvantaged families with children working fewer hours than middle income families with children.

In the US, the poor position of disadvantaged children arises mainly because market incomes are relatively low. Earnings, in particular, are $9 \%$ points lower (as a percentage of median disposable income), of which 5 points arises from lower wages, 4 points from relatively lower hours and 2 points from the relatively low earnings of families with children generally.

This can be contrasted with Australia, where D is close to the cross-national mean, transfers are greater than average, but market and earnings income is lower. Wage inequality in Australia is close to the cross-national mean, however, which implies that this difference all arises from relatively low employment hours worked by the parents of disadvantaged Australian children (Australia has the second lowest relative hours in Table 2).

A summary of the key results in Tables 2 and 3 are shown in Fig. 4 (only for countries with more than 1 million children, and with the $E_{Q 3}$ term combined with the small residual). In this figure, countries are sorted by relative family earnings $(E)$. The left-hand panel shows the decomposition into earnings, net social transfers, and capital and private transfer income (as per Table 2). The right-hand panel decomposes the earnings component of the left-hand panel (following Table 3). Earnings are decomposed into the cross-national mean earnings, that due to the relative wage level in that country, that due to the imputed relative hours of bottom-fifth families relative to middle-fifth families and the residual.

Bottom-fifth families in the Netherlands, for example, have a very high level of earnings (over $40 \%$ of median disposable income, compared to the cross-national mean of $27 \%$ ). Wage inequality is only slightly above the cross-national average, and so we infer that this earnings deviation mainly arises from more hours worked by disadvantaged families relative to middle income families (compared to the cross-national average) and relatively high earnings for middle income families compared to the overall population (the residual, which includes $E_{Q 3}$ ). South Korea, on the other hand, has more wage inequality than the 


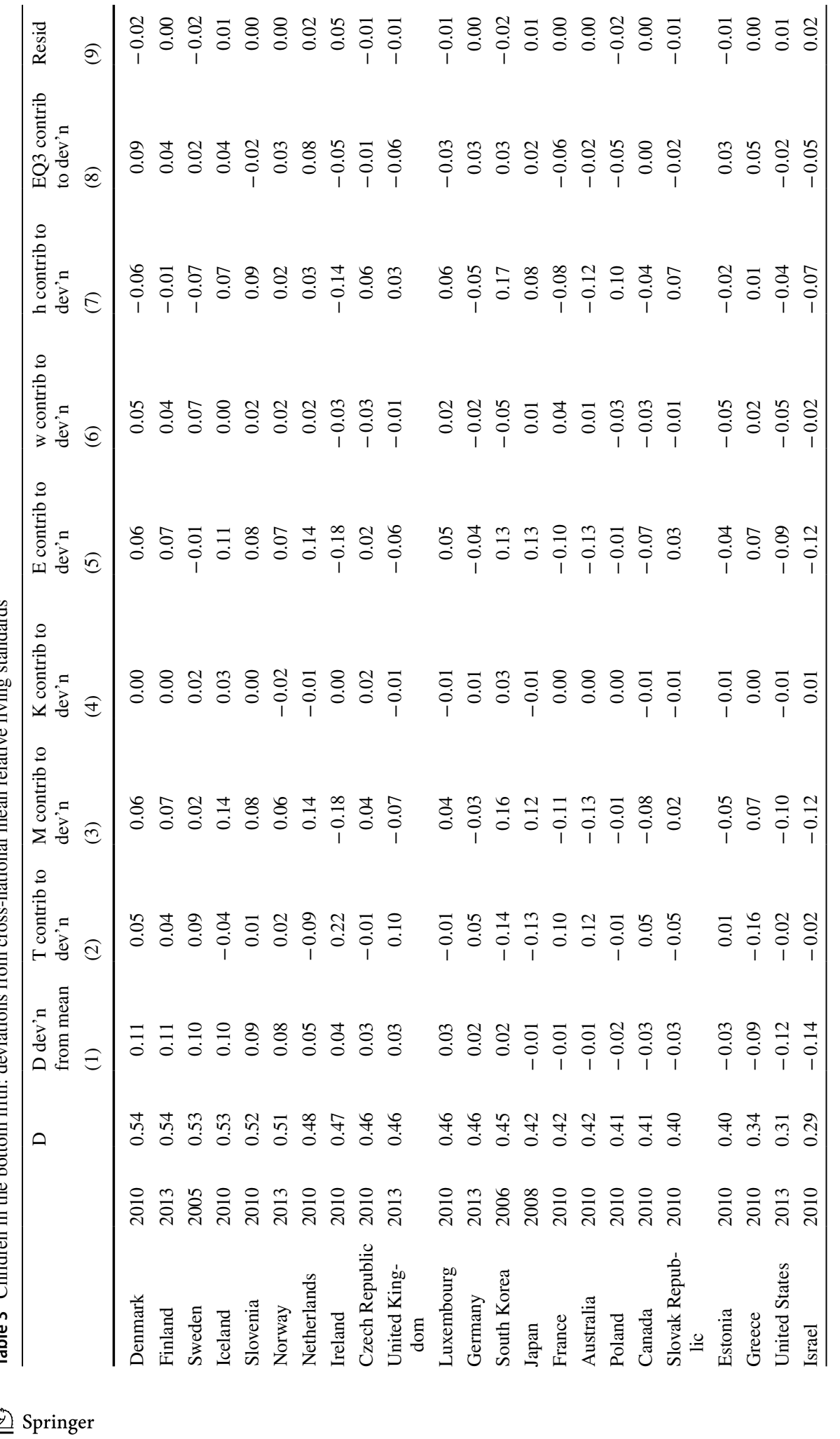




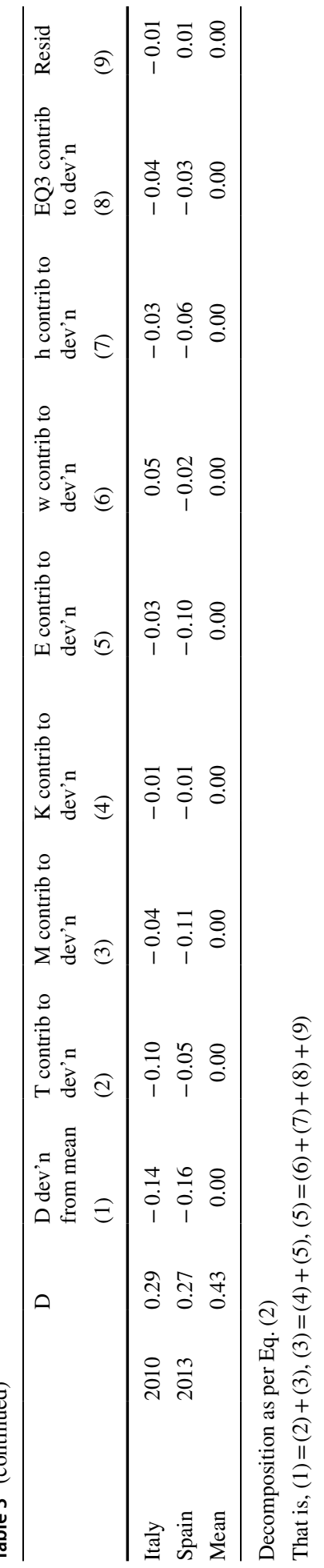




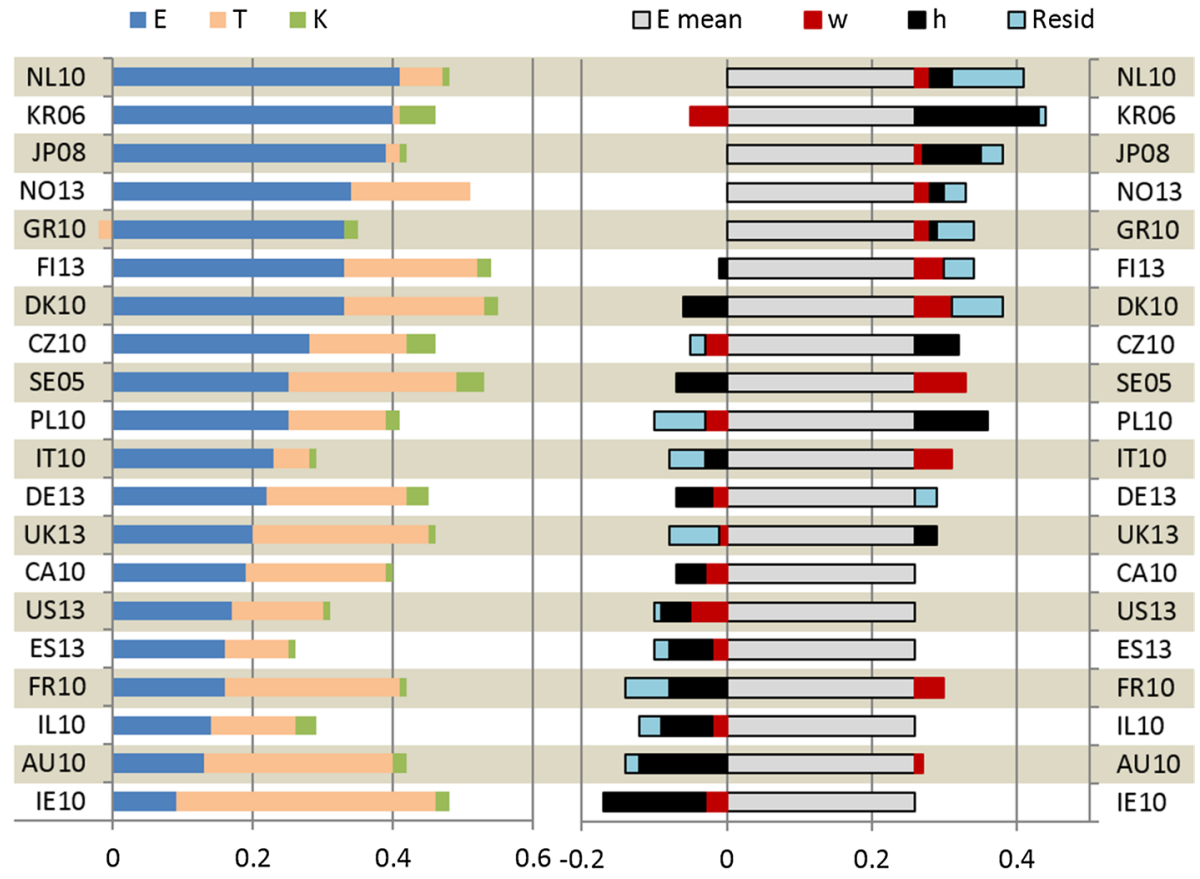

Fig. 4 Income decomposition summary. Notes Derived from Tables 2 and 3. Countries with less than $1 \mathrm{~m}$ children not shown

average country, which implies that relative working hours are very high in bottom-fifth countries-almost as high as middle income families (0.83 in Table 2).

Sweden (in 2005) is an example of a country with bottom-fifth relative earnings income close to the cross-national average. However, wage inequality is less than the cross-national average, implying that bottom-fifth families work relatively few hours.

The low bottom-fifth earnings in the English-speaking countries means that they are all in the lower half of Fig. 4. In Australia, this reflects relatively low hours worked in bottom-fifth households, while in the US and Canada, low wage rates also play a role. In the UK, the generally low level of earning income among families with children, rather than low earnings for the bottom-fifth specifically, is the main driver. Note that these decompositions into wage and hours effects all assume that the observed national patterns of wage inequality found in the OECD wage distribution dataset also apply to families with children. Further research on how wages vary across demographic categories and across nations is required to confirm these patterns.

\section{Conclusions}

Based on the most recent waves of LIS data for rich countries, market incomes and net transfers each 'explain' roughly similar proportions of the cross-national variation in the relative living standards of the bottom fifth of children. The negative correlation between the two is also strong, with countries with high levels of market income 
having relatively low levels of net transfers. While the time-series patterns shown here indicate that transfers often act as 'automatic stabilisers' during recessions, the negative cross-national correlation between transfers and earnings is also likely to be due to other explanations such as labour supply responses to high benefit levels and/or policy decisions in some countries to direct social expenditure to services such as employment and child care support rather than to transfers.

Different patterns in this 'income packaging' appear when we consider groupings of countries that share policy frameworks. Disadvantaged children in the English-speaking countries for example, all live in households with relatively low market incomes. Their average disposable income, however, varies widely because of differences in transfer income. Our calculations suggest that these low market incomes in disadvantaged families arise from relatively low employment hours in all countries, combined with relatively low bottom-end wage rates in the US and Canada.

Among the Nordic countries there are relatively similar levels of disposable income, with those countries with higher transfer levels tending to have lower levels of market income. A similar pattern applies across the four Western European countries in our study.

Looking at trends over the last two decades, most countries experienced an increase in transfer income during periods when market income decreased. In many cases, this was sufficient to maintain the relative living standards of the bottom fifth of children-bearing in mind that median income also decreased during these periods.

The average real incomes of disadvantaged children, however, varied more substantially across the economic cycle. Comparing real incomes prior to and after the financial crisis (generally 2010 vs 2007), disposable incomes decreased dramatically in Greece and Spain and substantially in Ireland, by a small amount in Australia, the US, the UK, Germany and the Netherlands, but increased in Norway, Canada and Denmark.

Acknowledgements We would like to thank for comments on earlier versions of this paper Willem Adema, David Grubb, Olivier Thevenon and Liz Washbrook, as well as other participants at seminars in Paris, Washington and Sigtuna. Washington, Sigtuna and New York. This research has been supported by the Australian Research Council (DP170103649), the Riksbankens Jubileumsfond (The Swedish Foundation for the Humanities and Social Sciences) (P12-0994:1) and the Advanced Research Collaborative at the Graduate Center, City University New York.

Open Access This article is distributed under the terms of the Creative Commons Attribution 4.0 International License (http://creativecommons.org/licenses/by/4.0/), which permits unrestricted use, distribution, and reproduction in any medium, provided you give appropriate credit to the original author(s) and the source, provide a link to the Creative Commons license, and indicate if changes were made.

\section{Appendix}

See Figs. 5, 6, 7 and 8. 


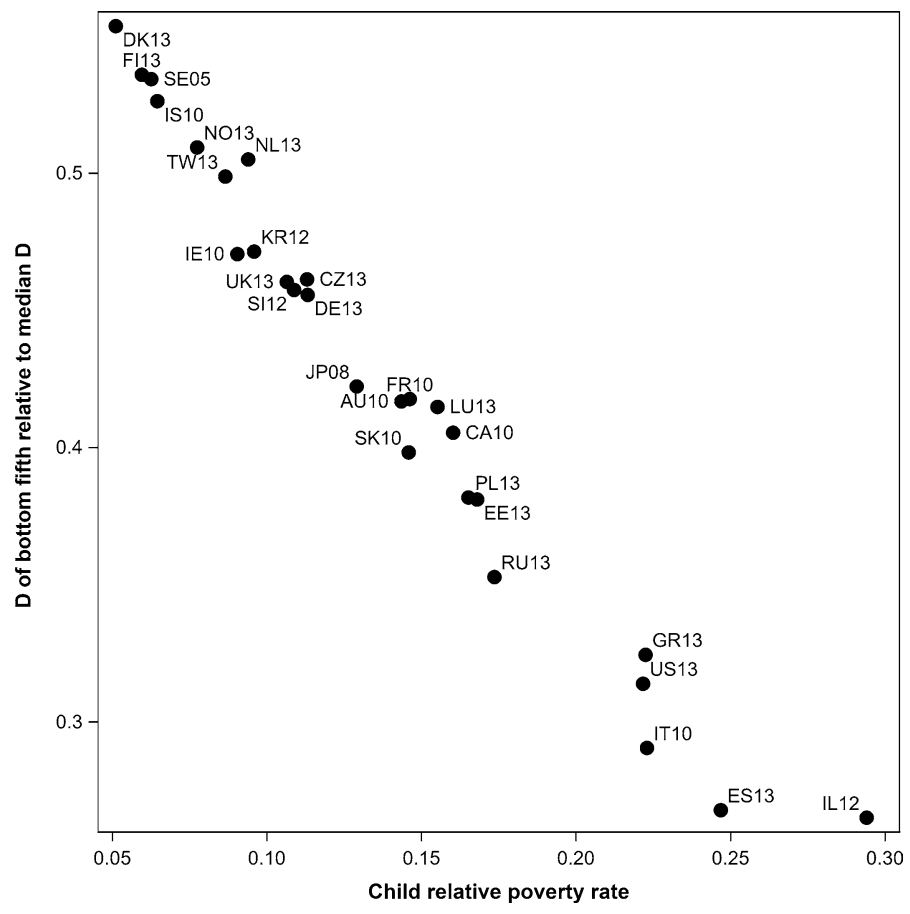

Fig. 5 Relative income poverty and relative mean income of the bottom fifth 


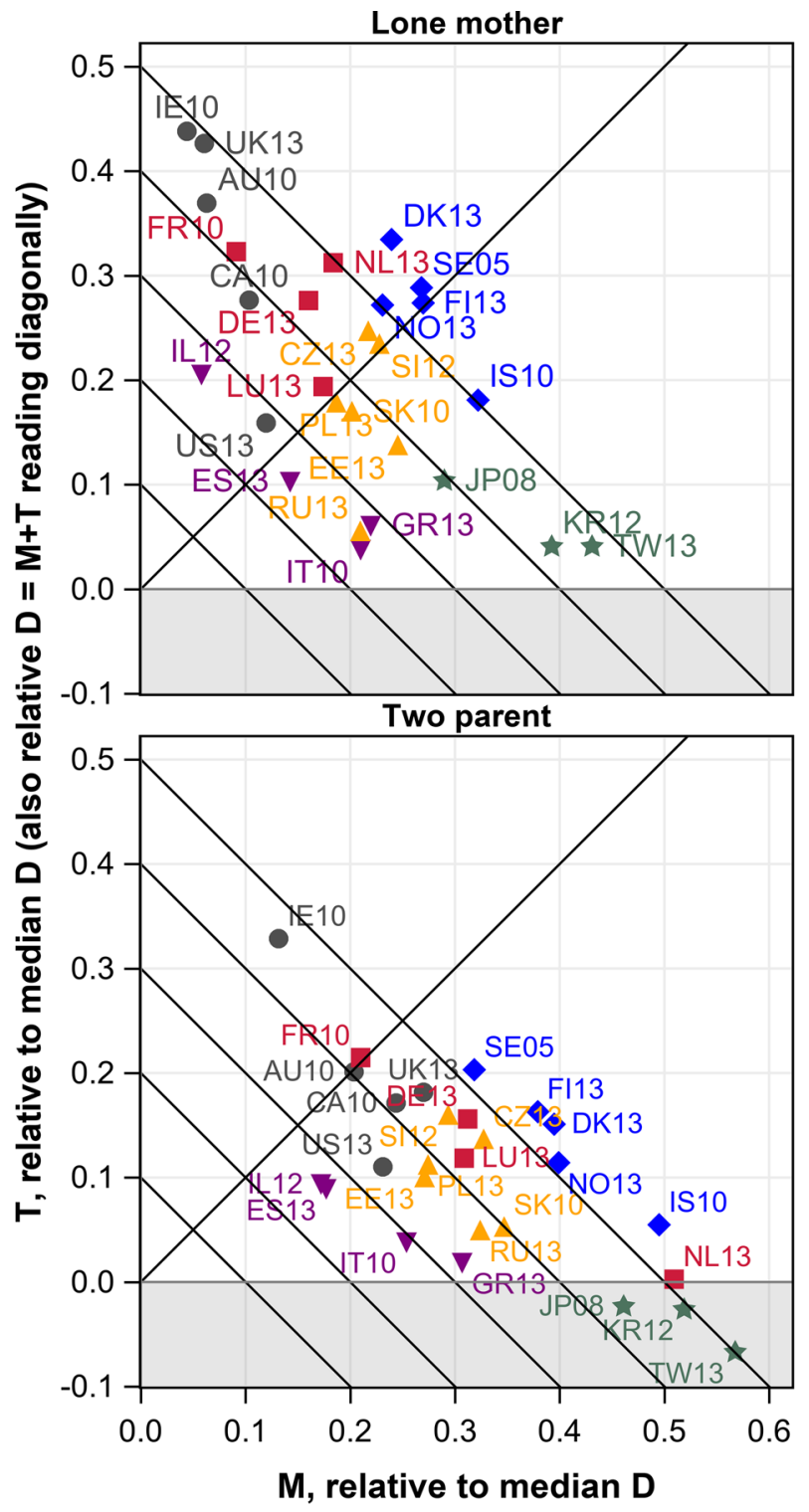

\section{East Asian Eastern Europe \\ English-speaking Mediterranean}

Fig. 6 Children in the bottom-fifth of disposable income: average market income (M), Net social transfers (T) and disposable income $(\mathrm{D}=\mathrm{M}+\mathrm{T})$ - all relative to median income (for Lone Mother and Two Parent families). Note The top panel shows the mean household incomes (relative to the overall median) of children in the bottom fifth (of all children) who are also in lone-mother households, and the bottom panel similarly for two-parent families. Lone father and 'other' family types are not shown 


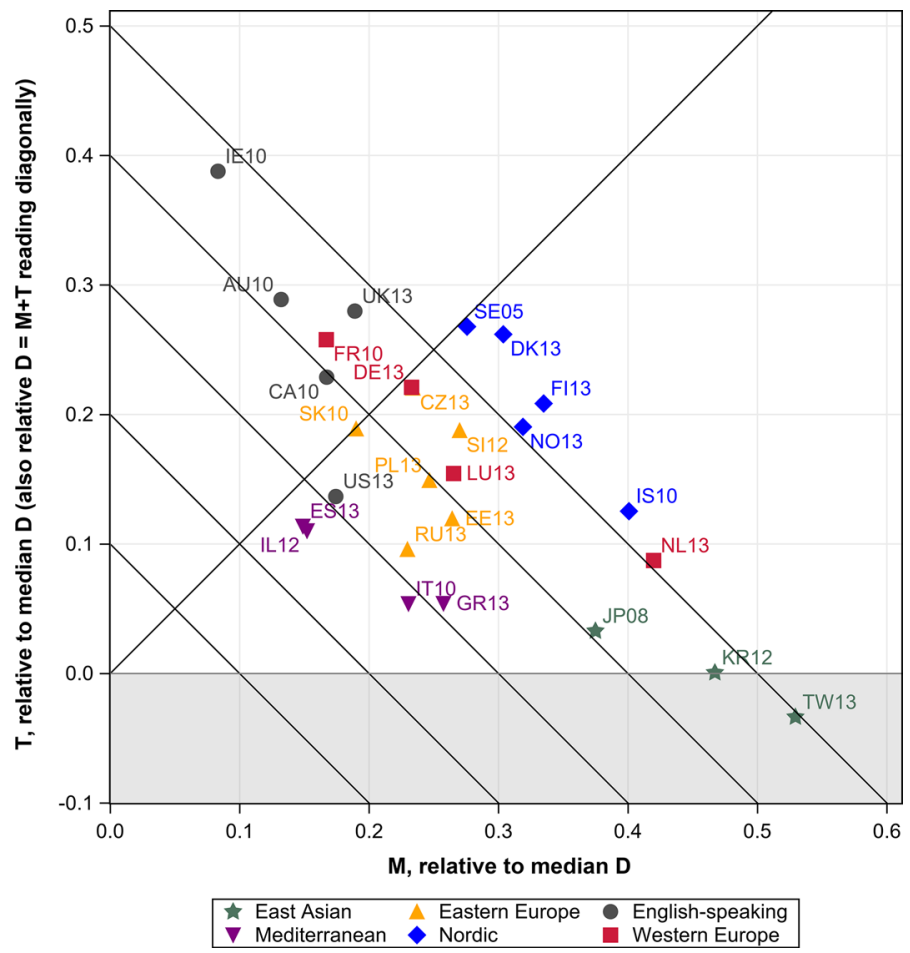

Fig. 7 Children in the bottom-fifth of disposable income: average market income (M), net social transfers (T) and disposable income $(\mathrm{D}=\mathrm{M}+\mathrm{T})$ - all relative to median income (children in households with no selfemployment income) 


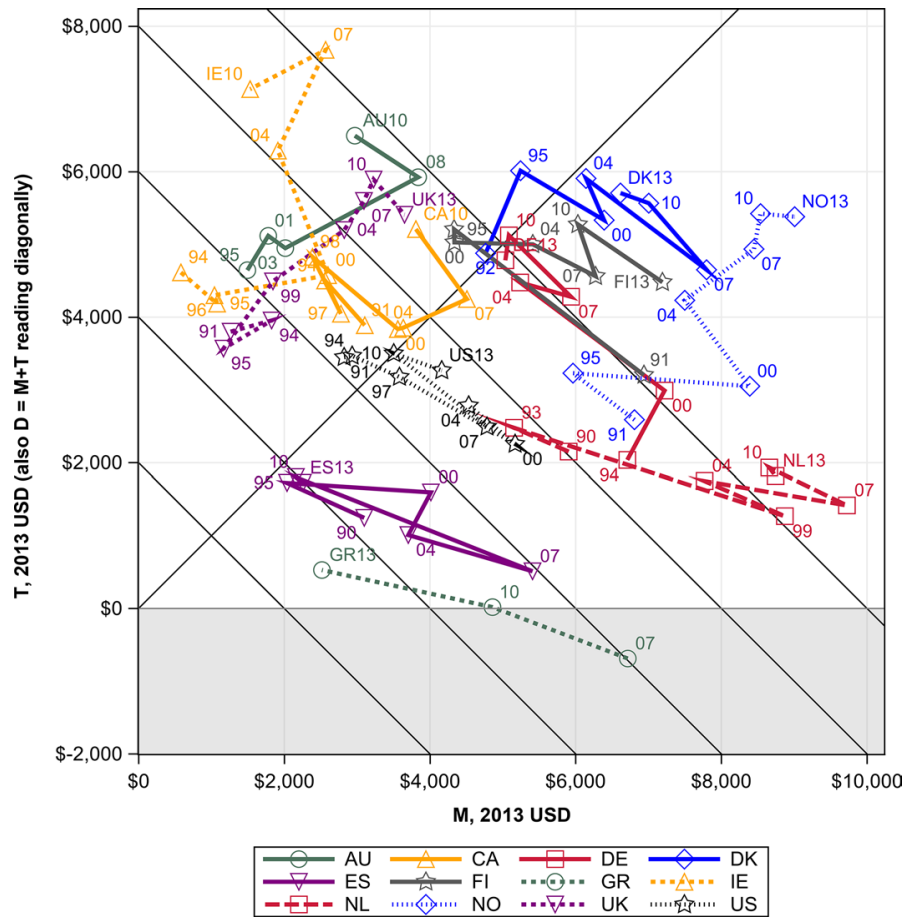

Fig. 8 Trends since the 1990s: 2013 USD (children in households with no self-employment income)

\section{References}

Adam, S., Brewer, M., \& Shephard, A. (2006). The poverty trade-off: Work incentives and income redistribution in Britain. London: Policy Press and Joseph Rowntree Foundation.

Bernstein, J., \& Shierholz, H. (2014). The minimum wage: A crucial labor standard that is well targeted to low- and moderate-income households. Journal of Policy Analysis and Management, 33(4), 1036-1043.

Bitler, M., Hoynes, H., \& Kuka E. (2014). Child poverty and the great recession in the United States. Innocenti Working Paper No. 2014-11, UNICEF Office of Research, Florence.

Björklund, A., \& Jäntti, M. (2011). Inkomstfördelningen i Sverige-SNS Välfärdsrapport 2011. Stockholm: SNS. (in Swedish).

Bradbury, B., \& Jäntti, M. (1999). Child poverty across industrialised nations. Innocenti Occasional Papers, Economic and Social Policy Studies, No. 71. Florence: UNICEF International Child Development Centre.

Bradbury, B., \& Jäntti, M. (2001a). Child poverty across twenty-five countries. In B. Bradbury, S. P. Jenkins, \& J. Micklewright (Eds.), The dynamics of child poverty in industrialised countries (pp. 62-91). Cambridge: CUP.

Bradbury, B., \& Jäntti, M. (2001b). Child poverty across the industrialized world: Evidence from the Luxembourg Income Study. In K. Vleminckx \& T. M. Smeeding (Eds.), Child well-being, child poverty and child policy in modern nations. Bristol: The Policy Press.

Chen, W.-H., \& Corak, M. (2008). Child poverty and changes in child poverty. Demography, 45(3), 537-553.

Chzhen, Y. (2014). Child poverty and material deprivation in the European Union during the great recession. Innocenti Research Centre, Working Paper No. 723. UNICEF Office of Research, Florence. 
Corak, M., Leitz, C., \& Sutherland H. (2005). The impact of tax and transfer systems on children in the European Union, Institute for the Study of Labor (IZA), Discussion Paper No. 1589. Bonn.

Dube, A. (2013). Minimum wages and the distribution of family incomes. Unpublished paper, December 30, 2013.

Esping-Andersen, G. (1990). The three worlds of welfare capitalism. Princeton: Princeton University Press.

Gornick, J., \& Jäntti, M. (2012). Child poverty in cross-national perspective: Lessons from the Luxembourg Income Study. Children and Youth Services Review, 34(3), 558-568.

Grubb, D., Singh, S., \& Tergeist, P. (2009). Activation policies in Ireland. OECD Social Employment and Migration Working Papers No. 75.

Korpi, W., \& Palme, J. (1998). The paradox of redistribution and strategies of equality: Welfare state institutions, inequality, and poverty in the Western Countries. American Sociological Review, 63(5), $661-687$.

Luxembourg Income Study Database (LIS). (2017). www.lisdatacenter.org (multiple countries; Data extracted April 2017). Luxembourg: LIS.

Mood, C., \& Jonsson, J. (2016). Trends in child poverty in Sweden: Parental and child reports. Child Indicators Research, 9(3), 825-854.

OECD. (2016). Earnings: Gross earnings: decile ratios. OECD Employment and Labour Market Statistics (Database). https://doi.org/10.1787/data-00302-en.

Sabia, J. J. (2014). Minimum wages: An antiquated and ineffective antipoverty tool. Journal of Policy Analysis and Management, 33(4), 1028-1036.

UNICEF. (2000). A league table of child poverty in rich nations. Innocenti Report Card No. 1, UNICEF Innocenti Research Centre, Florence.

Van Lanker, W., \& Van Mechelen, N. (2015). Universalism under siege? Exploring the association between targeting, child benefits and child poverty across 25 countries. Social Science Research, 50, 60-75.

Watson, D., Maître, B., Whelan, C. T. (2012). Work and Poverty in Ireland: An Analysis of the CSO Survey on Income and Living Conditions 2004-2010, Social Inclusion Report No. 3. Dublin: Department of Social Protection.

Weistra, T. (2016) Self-employment in the Netherlands. Presentation at OECD, June 24.

Whelan, C., Nolan, B., \& Maitre, B. (2017). Polarization or "Squeezed Middle" in the great recession? A comparative european analysis of the distribution of economic stress. Social Indicators Research, 133(1), 163-184.

Whiteford, P., \& Adema, W. (2007). What works best in reducing child poverty: A benefit or work strategy? OECD Social, Employment and Migration Working Papers No. 51. 